\title{
Author Index
}

Boulos, A.S. 1

Burguera, B. 236

Deshaies, E.M. 1

Feng, L. 160

Genevro, J. 236

Greenlee, R.G. Jr. 198

Guterman, L.R. 32, 70, 135

Hanel, R. 180

Hanel, R.A. 32

Harrigan, M.R. 70

Higashida, R.T. 160

Hopkins, L.N. 32, 70, 135
Horowitz, M.B. IX, 18, 101, Meyers, P.M. 160

122, 180, 198, 220, 236

Howington, J.U. 135

Ionita, C.C. 54

Jungreis, C.A. 198, 220

Kassam, A. 101, 236

Kerber, C.W. 135

Kim, S.H. 54

Kirmani, J.F. 54

Levy, D.I. 148

Levy, E.I. IX, 32, 70, 101, 122, 180, 236

Lunsford, L.D. VII
Ozgur, B.M. 148

Pollack, I. 220

Purdy, P.D. 18, 101, 198

Quisling, R.G. 220

Qureshi, A.I. 54

Ringer, A.J. 85

Siddiqui, A.M. 54

Spiro, R. 180

Xavier, A.R. 54 